\title{
American Brain Tumor Association
}

National Cancer Institute

\section{Source}

National Cancer Institute. American Brain Tumor Association. NCI Thesaurus. Code C39309.

The American Brain T umor Association (ABTA) is a not-profit independent global organization that funds brain tumor research and provides the information patients need to make educated decisions about their health care. ABTA has a special funding program for scientists sponsored by $\mathrm{NIH}$, and sponsors a research study focusing on familial brain tumors. 